\title{
Computational Insights into the Isomerism of Hexacoordinate Metal-Sarcophagine Complexes: The Relationship between Structure and Stability
}

\author{
Andrés G. Algarra*[a]
}

Keywords: Density functional calculations / Energy analysis / Macrocycles / Transition metals / Isomers

\begin{abstract}
The hexacoordinate complexes that the macrobicyclic ligands $\left\{\left(\mathrm{NH}_{3}\right)_{2} \mathrm{sar}^{2+}\right.$ and $\left\{\left(\mathrm{NMe}_{3}\right)_{2} \mathrm{Sar}\right\}^{2+}(\mathrm{sar}=3,6,10,13,16,19$-hexaazabicyclo[6.6.6]icosane) form with transition metals such as $\mathrm{Co}^{\mathrm{III}}, \mathrm{Co}^{\mathrm{II}}$ and $\mathrm{Cu}^{\mathrm{II}}$ can adopt several isomeric structures. In this article, we have firstly employed DFT methods to compute the relative stability of their $\Delta-o b_{3}, \Delta-o b_{2} l e l, \Delta-l e l_{2} o b$ and $\Delta-\mathrm{lel}_{3}$ isomers, as well as the activation barriers for their interconversion. In agreement with the experimental data, the results show that, in general, the different isomers of the $\mathrm{Co}^{\mathrm{III}}$ and $\mathrm{Co}^{\mathrm{II}}$ complexes present similar free energies, whereas the $\mathrm{Cu}^{\mathrm{II}}$ complexes show a strong tendency towards the $l e l_{3}$ form. In addition, the interplay between the structure and stability of these species has been studied by combining
\end{abstract}

shape maps with a distortion/interaction energy analysis. In contrast to the geometries close to the ideal octahedron that all the studied Co complexes present, the $l l_{3}$ structures of $\left[\mathrm{Cu}\left\{\left(\mathrm{NH}_{3}\right)_{2} \mathrm{Sar}\right\}\right]^{4+}$ and $\left[\mathrm{Cu}\left\{\left(\mathrm{NMe}_{3}\right)_{2} \mathrm{Sar}\right\}\right]^{4+}$ are better described as trigonal prisms. In such structures the ligand adopts a conformation significantly more stable than in the other isomers, and this drives the formation of $\operatorname{lel}_{3}-\left[\mathrm{Cu}\left\{\left(\mathrm{NH}_{3}\right)_{2} \mathrm{Sar}\right\}\right]^{4+}$ and $\mathrm{lel}_{3}-\left[\mathrm{Cu}\left\{\left(\mathrm{NMe}_{3}\right)_{2} \mathrm{Sar}\right\}\right]^{4+}$. Overall, the results show a clear relationship between the stability of a given isomer and its degree of distortion with respect to the ideal octahedron (or trigonal prism), with the latter being ultimately dependent on the transition metal and its radius.

\section{Introduction}

The complexes that macrobicyclic hexamine ligands of the sarcophagine family (sar $=3,6,10,13,16,19$-hexaazabicyclo[6.6.6]icosane; Scheme 1) form with transition metals have been largely studied in recent decades owing to their central role in classical coordination chemistry. ${ }^{[1]}$ These studies have proven that such complexes are typically hexacoordinate and show high thermodynamic stability and kinetic inertness. ${ }^{[2]}$ This has led to important applications, particularly in the field of medicinal chemistry, in which the complexes formed between copper-64 and different sar derivatives are currently employed for positron emission tomography (PET) imaging. ${ }^{[3]}$

Importantly, all the hexacoordinate complexes formed between the family of sar ligands and transition metals are chiral. Firstly, two enantiomers with identical stabilities can exist as a result of the helicity of the central $\mathrm{C}-\mathrm{C}$ bond of the ethylenediamine (en) chelate rings relative to the effective $C_{3}$ axis of the complex (passing through the centroids of the faces without edges spanned by the chelate rings and the transition metal), and these are designated $\Delta$ and $\Lambda$ ac-

[a] Department of Organic Chemistry, Arrhenius Laboratory, Stockholm University,

10691 Stockholm, Sweden

E-mail: algarra@organ.su.se http://www.organ.su.se

Supporting information for this article is available on the WWW under http://dx.doi.org/10.1002/ejic.201402984. a)

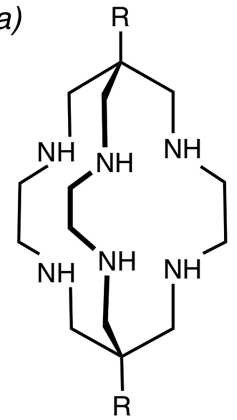

$\mathrm{R}=\mathrm{H} \quad \rightarrow$ sar

$\mathrm{R}=\left(\mathrm{NH}_{3}\right)^{+} \rightarrow\left\{\left(\mathrm{NH}_{3}\right)_{2} \mathrm{sar}\right\}^{2+}$

$\mathrm{R}=\left(\mathrm{NMe}_{3}\right)^{+} \rightarrow\left\{\left(\mathrm{NMe}_{3}\right)_{2} \mathrm{sar}\right\}^{2+}$ b)

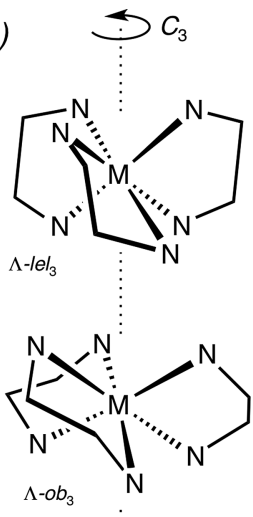

Scheme 1. (a) Structure of the sarcophagine ligand (sar) and two of its derivatives. (b) Illustration of the central ethylenediamine chelate rings on the $\Lambda-o b_{3}$ and $\Lambda-l e l_{3}$ conformations of a generic metal-sarcophagine complex along their $C_{3}$ axis. Note that for clarity the ligand caps are not shown.

cording to the IUPAC nomenclature rules. ${ }^{[4]}$ Each of these enantiomers can, in addition, exist in four diastereomeric forms depending on the conformation adopted by each of the three central chelate rings of the ligand (see Scheme 1), which can essentially either be parallel to the $C_{3}$ axis of the complex (designated "lel") or oblique to this axis (designated " $o b$ "). ${ }^{[5]}$ As a result, eight diastereomeric/enantiomeric forms $\left(\Delta-o b_{3}, \Delta-o b_{2} l e l, \Delta-l e l_{2} o b, \Delta-l e l_{3}, \Lambda\right.$ - $o b_{3}$, 
$\Lambda-o b_{2} l e l, \Lambda-l e l_{2} o b$ and $\Lambda-l e l_{3}$ ) may be considered to exist. A further source of chirality comes from the asymmetry of the six secondary $\mathrm{N}$ donors that coordinate to the metal centre. Fortunately, it turns out that all of these centres show the same configuration for a given complex in such a way that the $\Delta$ enantiomers are paired with $(R)-\mathrm{N}$ and the $\Lambda$ with $(S)-\mathrm{N},{ }^{[6]}$ and therefore neither lead to more isomers nor are they usually included in the complex description. Finally, the sarcophagine complexes formed with Jahn-Teller-active transition metals such as $\mathrm{Cu}^{\mathrm{II}}$ or low-spin $\mathrm{Co}^{\mathrm{II}}$ show an even larger number of isomers. ${ }^{[7]}$ In these cases the octahedral symmetry of each of the eight diastereomeric/enantiomeric forms can undergo Jahn-Teller distortion along each Cartesian axis to give rise to three minima (the socalled "Mexican hat" model). ${ }^{[8]}$ Nevertheless, the activation barrier for the conversion between them is usually small, ${ }^{[9]}$ and average structures are observed at room temperature. ${ }^{[10]}$

Despite all of these sources of isomerism, the description of metal-sarcophagine complexes is usually limited to the indication of the lel or $o b$ conformations of the central en chelate rings, which can lead to the four isomers $o b_{3}, o b_{2} l e l$, $l e l_{2} \mathrm{ob}$ and $l e l_{3}$. The preferred conformation depends both on the encapsulated metal and its oxidation state, and on the structure of the sarcophagine ligand, especially the nature of the groups in the apical positions. Experimental studies have shown, for instance, that whereas both $\mathrm{Co}^{\mathrm{II}}$ complexes $\left[\mathrm{Co}\left\{\left(\mathrm{NH}_{3}\right)_{2} \mathrm{Sar}\right\}\right]^{4+}$ and $\left[\mathrm{Co}\left\{\left(\mathrm{NMe}_{3}\right)_{2} \mathrm{Sar}\right\}\right]^{4+}$ adopt a $\mathrm{lel}_{3}$ conformation in aqueous solution, their oxidation to $\mathrm{Co}^{\mathrm{III}}$ generates complexes with $l e l_{3}$ and $\mathrm{ob}_{3}$ conformations, respectively. ${ }^{[2 a]}$ It is noteworthy that the conformational changes in the case of the $\left[\mathrm{Co}\left\{\left(\mathrm{NMe}_{3}\right)_{2} \mathrm{Sar}\right\}\right]^{5+/ 4+}$ couple have been hypothesised to explain the fact that its rate constant of electron self-exchange is between one and two orders of magnitude smaller than that of $\left[\mathrm{Co}\left\{\left(\mathrm{NH}_{3}\right)_{2}-\right.\right.$ sar $\}]^{5+},{ }^{2 a]}$ as in such case the oxidation (or reduction) process would also imply a structural reorganisation. However, not all transition metals show such a feature, and regardless of the substituent on the sarcophagine ligand, their complexes with $\mathrm{Cu}^{\mathrm{II}}$ do not seem to be prone to a conformation other than $\mathrm{lel}_{3} \cdot{ }^{[\mathrm{b}]}$

From a computational point of view, most of the studies on the isomerism of metal-sarcophagine complexes appeared in the 1980s and 1990s, in parallel to their synthesis. ${ }^{[2 \mathrm{c}, 11,12]}$ For the most part, these used molecular mechanic (MM) calculations with different force fields, and despite their limitations were, for instance, successfully employed to analyse the relative stability of the different isomers of $[\mathrm{Co}(\mathrm{sar})]^{3+},{ }^{2 \mathrm{cc}]}$ or the redox properties of a number of (hexaamine)Co ${ }^{\text {III/II }}$ couples. ${ }^{[13]}$ In fact, the former study already highlighted a relationship between $\mathrm{M}-\mathrm{N}$ distances, the distortions with respect to the octahedral geometry, and the stability of the isomers. However, despite the interest in those findings, little attention has been paid to them since. Thus, based on the available experimental information, in this work we have further analysed the relationship between those factors in the complexes that $\mathrm{Co}^{\mathrm{III}}, \mathrm{Co}^{\mathrm{II}}$ and $\mathrm{Cu}^{\mathrm{II}}$ form with the sarcophagine-derived ligands $\left\{\left(\mathrm{NH}_{3}\right)_{2} \mathrm{sar}\right\}^{2+}$ and $\left\{\left(\mathrm{NMe}_{3}\right)_{2} \mathrm{Sar}^{2+}\right.$. To do so, we first employed DFT methods to characterise the structure and relative stability of all the isomers that each metal-ligand combination can form, as well as the transition states for their interconversion. The ground-state structures of those isomers were then analysed by using the continuous symmetry measures (CSM) approach to determine their degree of distortion versus the octahedral geometry, and their relative stabilities were studied with the help of distortion/interaction analysis. The results reported here clearly confirm the existence of a relationship between such factors.

\section{Results and Discussion}

\section{Structure of the Isomers and Continuous Symmetry Measures}

The $o b_{3}, o b_{2} l e l, l e l_{2} o b$ and $l e l_{3}$ diastereoisomers of the hexacoordinate complexes that $\mathrm{Co}^{\mathrm{III}}, \mathrm{Co}^{\mathrm{II}}$ and $\mathrm{Cu}^{\mathrm{II}}$ form with $\left\{\left(\mathrm{NH}_{3}\right)_{2} \mathrm{Sar}\right\}^{2+}$ and $\left\{\left(\mathrm{NMe}_{3}\right)_{2} \mathrm{sar}^{2+}\right.$, as well as the transition states for their interconversion, have been computed by DFT methods. The structures thus obtained compared well with the available crystallographic data (see the Supporting Information). Importantly, all of the computed structures belong to the $\Delta$ enantiomer; their $\Lambda$ mirror images have not been optimised owing to their identical stabilities. Moreover, previous studies have shown that the computed structures can have a certain degree of symmetry, that is, the $o b_{3}$ and $l e l_{3}$ can adopt $D_{3}$ and $C_{3}$ point groups respectively, whereas the different orientation of the central en chelate rings on the intermediate $\mathrm{ob}_{2} l e l$ and $l e l_{2} \mathrm{ob}$ conformation reduces their maximum symmetry to the $C_{2}$ point group. ${ }^{[14]}$ Thus, in all cases optimisations were carried out both with and without symmetry restrictions, and only the lowest gas-phase energy structures are discussed here. Note that no symmetry restriction was applied to the transition states.

Optimisation of the $D_{3}-o b_{3}, C_{2}-o b_{2} l e l, C_{2}-l e l_{2} o b$ and $C_{3^{-}}$ $\mathrm{lel}_{3}$ diastereoisomers of the complexes formed between $\mathrm{Co}^{\mathrm{III}}$ and the sarcophagine ligands $\left\{\left(\mathrm{NH}_{3}\right)_{2} \mathrm{sar}\right\}^{2+}$ and $\left\{\left(\mathrm{NMe}_{3}\right)_{2} \mathrm{Sar}^{2+}\right.$ generates structures with similar or slightly lower energy (differences of ca. $0.5 \mathrm{kcal} \mathrm{mol}^{-1}$ ) than their $C_{1}$ analogues. In contrast, those formed with $\mathrm{Co}^{\mathrm{II}}$ and $\mathrm{Cu}^{\mathrm{II}}$ show a different behaviour due to their Jahn-Teller-active nature. ${ }^{[7]}$ For these, optimisation of octahedral geometries with equivalent $\mathrm{M}-\mathrm{L}$ distances is known to lead to conical intersections with energies higher than their distorted minima, ${ }^{[8 a, 15]}$ so $C_{1}$ structures were computed. Optimisation of the $\mathrm{ob}_{2} l e l$ and $l e l_{2} \mathrm{Ob}$ diastereoisomers of the complexes between $\mathrm{Co}^{\mathrm{II}}$ and $\mathrm{Cu}^{\mathrm{II}}$ and both sarcophagine ligands was also started under the $C_{2}$-symmetry constraint. Interestingly, the $\mathrm{C}_{2}-\mathrm{ob}_{2} l e l$-optimised structures proved to correspond to transition states for the interconversion between two Jahn-Teller isomers, so their stable $C_{1}$ analogues are shown here. The $\mathrm{C}_{2}-\mathrm{ob}_{2} l e l$ isomers, however, were found to be stable minima at the optimisation level of theory, and comparison to their $C_{1}$-optimised analogues showed negligible geometrical and energetic differences. 
The structures of the different diastereoisomers of $\left[\mathrm{Co}\left\{\left(\mathrm{NH}_{3}\right)_{2} \mathrm{Sar}\right\}\right]^{5+}$ as well as the transition states for their interconversion are included in Figure 1, whereas selected geometric parameters (i.e., $\mathrm{M}-\mathrm{N}$ bonding lengths and $\mathrm{N}-$ $\mathrm{C}-\mathrm{C}-\mathrm{N}$ dihedral angles of the central en chelate rings) for all the studied complexes are given in Table 1. ${ }^{[16]}$ In general, the analysis of these structures shows that the $\mathrm{N}-\mathrm{C}-\mathrm{C}-\mathrm{N}$ dihedral angles associated with the central en chelate rings define the $o b$ or lel conformation of each strap, with significantly different values of approximately -45 and $+50^{\circ}$, respectively. Furthermore, the transition states for their interconversion show $\mathrm{N}-\mathrm{C}-\mathrm{C}-\mathrm{N}$ dihedral angles near $0^{\circ}$, although in some cases deviations up to $9^{\circ}$ appear, probably due to the geometric constraints. In addition, it is observed that in all cases the series of interconversions from the $o b_{3}$ to $l_{e} l_{3}$ conformations are accompanied by an increase in the average $\mathrm{M}-\mathrm{L}$ distance. In relation to the differences associated with the presence of hydrogen or methyl groups in the apical positions of the macrobicycle, it is found that their different electron-donating characters only promote small changes in the $\mathrm{M}-\mathrm{N}$ distances, which become slightly shorter (up to ca. $0.04 \AA$ ) when the ligand $\left\{\left(\mathrm{NH}_{3}\right)_{2} \mathrm{sar}\right\}^{2+}$ is substituted by $\left\{\left(\mathrm{NMe}_{3}\right)_{2} \mathrm{sar}\right\}^{2+}$. Nevertheless, such structural analysis cannot be completed if the coordination environment around the metal centres is not taken into account, as despite their hexacoordination they present different degrees of distortion with respect to the ideal octahedral or trigonal-prismatic geometries. For that purpose we have employed the CSM approach (see the Computational Details), which in the case of hexacoordination makes use of two measures, $S\left(O_{h}\right)$ and $S($ itp), to fully characterise each ground-state structure in a two-dimensional space so-called symmetry map (see Figure 2). Alvarez, Avnir et al. have carried out thorough studies on the properties of the symmetry maps of six-coordinate metal compounds (among others), so only a short summary will be given here. ${ }^{[1]}$ The two measures $S\left(O_{h}\right)$ and $S(\mathrm{itp})$ determine quantitatively the distance of a structure from the perfect symmetry of the octahedron and trigonal prism, respectively. The former is characterised by $S\left(O_{h}\right)=0$ and $S(\mathrm{itp})=16.73$, whereas the latter shows $S\left(O_{h}\right)=16.73$ and $S(\mathrm{itp})=0$. Interconversion between these idealised polyhedra along the Bailar trigonal twist is represented in the symmetry map by a curved line with intermediate $S\left(O_{h}\right)$ and $S($ itp) values. However, structures often present additional distortions that also have an effect on the continuous symmetry measures and therefore affect their position in the symmetry map. Among them, the Jahn-Teller tetragonal distortion is especially important in the present case given the nature of the $\mathrm{Co}^{\mathrm{II}}$ and $\mathrm{Cu}^{\mathrm{II}}$ complexes. The extent of such distortion is quantified by the $\Delta$ parameter, which represents the difference between axial and equatorial bond lengths. Jahn-Teller bondstretching distortions acting on the structures over the Bailar twist line with equivalent $\mathrm{M}-\mathrm{L}$ distances $(\Delta=0)$ appear on the symmetry map for hexacoordination as curves quite parallel to the previous one, and for comparative purposes those for $\Delta$ values of 0.2 and 0.4 have been included in Figure 2.

Thus, the data in Figure 2 (a) for the non-JT-active $\mathrm{Co}^{\mathrm{III}}$ complexes with $\left\{\left(\mathrm{NH}_{3}\right)_{2} \mathrm{Sar}\right\}^{2+}$ and $\left\{\left(\mathrm{NMe}_{3}\right)_{2} \mathrm{Sar}\right\}^{2+}$ indicates that, as expected, their $D_{3}-o b_{3}$ and $C_{3}-l e l_{3}$ conformers appear along the Bailar twist curve as they feature equiva-
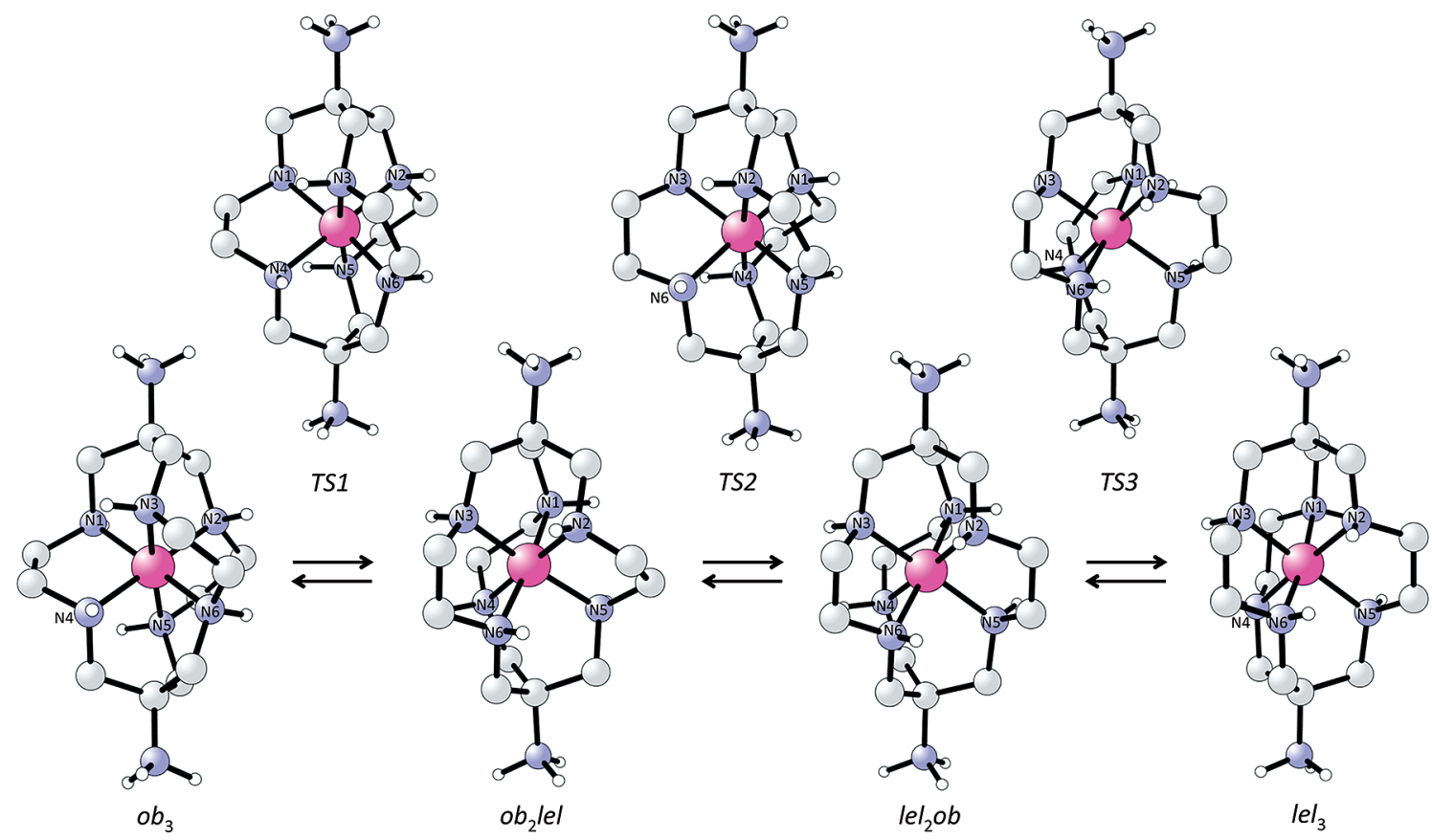

Figure 1. Optimised structures of the different diastereoisomers of $\left[\mathrm{Co}\left\{\left(\mathrm{NH}_{3}\right)_{2} \mathrm{Sar}\right\}\right]^{5+}$ and the transition states for their interconversion. See Table 1 for structural data. Carbon-bound hydrogen atoms have been omitted for clarity. Colour code: carbon (grey), nitrogen (blue), cobalt (pink), hydrogen (white). 
Table 1. Summary of selected distances $(d[\AA])$, dihedral angles $\left(\Phi\left[^{\circ}\right]\right)$ and octahedron $S\left(O_{h}\right)$ and trigonal prism $S($ itp $)$ symmetry measures for the computed diastereoisomers of the hexacoordinate complexes that $\mathrm{Co}^{\mathrm{III}}, \mathrm{Co}^{\mathrm{II}}$ and $\mathrm{Cu}^{\mathrm{II}}$ form with the ligands $\left\{\left(\mathrm{NH}_{3}\right)_{2} \mathrm{Sar}^{2+}\right.$ and $\left\{\left(\mathrm{NMe}_{3}\right)_{2} \mathrm{Sar}^{2+}\right.$, as well as transition states for their interconversion. ${ }^{[\mathrm{a}]}$

\begin{tabular}{|c|c|c|c|c|c|c|c|c|c|c|c|c|}
\hline Species & $\begin{array}{l}\text { Average } \\
d(\mathrm{M}-\mathrm{N})\end{array}$ & $d(\mathrm{M}-\mathrm{N} 1)$ & $d(\mathrm{M}-\mathrm{N} 2)$ & $d(\mathrm{M}-\mathrm{N} 3)$ & $d(\mathrm{M}-\mathrm{N} 4)$ & $d(\mathrm{M}-\mathrm{N} 5)$ & $d(\mathrm{M}-\mathrm{N} 6)$ & $\begin{array}{c}\Phi \\
(\mathrm{N} 1-\mathrm{C}-\mathrm{C}-\mathrm{N} 4)\end{array}$ & $\begin{array}{c}\Phi \\
(\mathrm{N} 2-\mathrm{C}-\mathrm{C}-\mathrm{N} 5)\end{array}$ & $\begin{array}{c}\Phi \\
(\mathrm{N} 1-\mathrm{C}-\mathrm{C}-\mathrm{N} 4)\end{array}$ & $S\left(O_{h}\right)$ & $S$ (itp) \\
\hline \multicolumn{13}{|c|}{$\left[\mathrm{Co}\left\{\left(\mathrm{NH}_{3}\right)_{2} \mathrm{Sar}\right\}\right]^{5+}$} \\
\hline$D_{3}-o b_{3}$ & 2.015 & 2.015 & 2.015 & 2.015 & 2.015 & 2.015 & 2.015 & -43.5 & -43.5 & -43.5 & 0.08 & 15.17 \\
\hline TS1 & 2.024 & 2.03 & 2.019 & 2.024 & 2.019 & 2.03 & 2.024 & -45.7 & -45.7 & 1.5 & - & - \\
\hline$C_{2}-o b_{2} l e l$ & 2.034 & 2.025 & 2.018 & 2.059 & 2.018 & 2.025 & 2.059 & -46.0 & -46.0 & 52.0 & 0.56 & 13.27 \\
\hline TS2 & 2.041 & 2.038 & 2.027 & 2.056 & 2.026 & 2.036 & 2.064 & -49.4 & 0.9 & 51.7 & - & - \\
\hline $\mathrm{C}_{2}-\mathrm{lel}_{2} \mathrm{ob}$ & 2.047 & 2.023 & 2.056 & 2.061 & 2.023 & 2.061 & 2.056 & -49.8 & 52.6 & 52.6 & 0.82 & 12.14 \\
\hline TS3 & 2.041 & 2.03 & 2.032 & 2.056 & 2.005 & 2.052 & 2.073 & -6.4 & 52.3 & 52.6 & - & - \\
\hline $\mathrm{C}_{3}-\mathrm{lel}_{3}$ & 2.047 & 2.047 & 2.047 & 2.047 & 2.047 & 2.047 & 2.047 & 54.3 & 54.3 & 54.3 & 0.44 & 12.39 \\
\hline \multicolumn{13}{|c|}{$\left[\mathrm{Co}\left\{\left(\mathrm{NMe}_{3}\right)_{2} \operatorname{sar}\right\}\right]^{5+}$} \\
\hline$D_{3}-o b_{3}$ & 2.003 & 2.003 & 2.003 & 2.003 & 2.003 & 2.003 & 2.003 & -43.8 & -43.8 & -43.8 & 0.08 & 15.06 \\
\hline TS1 & 2.013 & 2.018 & 2.009 & 2.013 & 2.009 & 2.018 & 2.013 & -46.0 & -46.0 & 2.6 & - & - \\
\hline$C_{2}-o b_{2} l e l$ & 2.022 & 2.01 & 2.007 & 2.049 & 2.007 & 2.01 & 2.049 & -46.5 & -46.5 & 51.5 & 0.59 & 13.14 \\
\hline TS2 & 2.033 & 2.021 & 2.024 & 2.051 & 2.021 & 2.024 & 2.056 & -49.5 & 3.4 & 51.8 & - & - \\
\hline$C_{2}-l e l_{2} \mathrm{ob}$ & 2.039 & 2.014 & 2.058 & 2.046 & 2.014 & 2.046 & 2.058 & -50.3 & 52.2 & 52.2 & 1.07 & 11.34 \\
\hline TS3 & 2.024 & 1.992 & 2.036 & 2.053 & 2.011 & 2.012 & 2.037 & -8.6 & 50.8 & 51.5 & - & - \\
\hline $\mathrm{C}_{3}-\mathrm{lel}_{3}$ & 2.036 & 2.037 & 2.037 & 2.037 & 2.035 & 2.035 & 2.035 & 51.8 & 51.8 & 51.8 & 0.71 & 11.28 \\
\hline \multicolumn{13}{|c|}{$\left[\mathrm{Co}\left\{\left(\mathrm{NH}_{3}\right)_{2} \mathrm{Sar}\right\}\right]^{4+}$} \\
\hline$o b_{3}$ & 2.094 & 2.248 & 2.005 & 2.021 & 2.028 & 2.006 & 2.254 & -43.8 & -42.4 & -43.4 & 0.48 & 14.49 \\
\hline TS1 & 2.103 & 2.271 & 2.026 & 2.027 & 2.048 & 2.244 & 2.003 & -45.6 & -45.3 & 0.9 & - & - \\
\hline $\mathrm{ob}_{2} \mathrm{lel}$ & 2.113 & 2.017 & 2.028 & 2.33 & 1.995 & 2.259 & 2.049 & -44.1 & -46.5 & 57.5 & 1.17 & 12.57 \\
\hline TS2 & 2.121 & 2.007 & 2.044 & 2.356 & 2.006 & 2.258 & 2.057 & -46.4 & -0.8 & 57.3 & - & - \\
\hline$C_{2}-l e l_{2} \mathrm{ob}$ & 2.132 & 1.998 & 2.069 & 2.329 & 1.998 & 2.329 & 2.069 & -46.7 & 57.6 & 57.6 & 1.76 & 10.35 \\
\hline TS3 & 2.153 & 2.015 & 2.074 & 2.373 & 2.004 & 2.350 & 2.101 & 3.9 & 57.8 & 58.5 & - & - \\
\hline $\mathrm{lel}_{3}$ & 2.141 & 2.312 & 2.044 & 2.067 & 2.074 & 2.029 & 2.317 & 58.1 & 54.3 & 58.7 & 1.67 & 9.72 \\
\hline \multicolumn{13}{|c|}{$\left[\mathrm{Co}\left\{\left(\mathrm{NMe}_{3}\right)_{2} \operatorname{sar}\right\}\right]^{4+}$} \\
\hline$o b_{3}$ & 2.08 & 2.228 & 1.997 & 2.013 & 2.012 & 1.998 & 2.23 & -43.7 & -43.0 & -43.5 & 0.31 & 14.44 \\
\hline TS1 & 2.091 & 2.015 & 2.256 & 2.013 & 2.23 & 2.035 & 1.997 & -45.3 & -45.9 & 1.7 & - & - \\
\hline $\mathrm{ob}_{2} \mathrm{lel}$ & 2.119 & 1.992 & 2.070 & 2.296 & 1.992 & 2.295 & 2.071 & -46.7 & 56.8 & 56.8 & 1.25 & 12.12 \\
\hline TS2 & 2.045 & 1.999 & 2.232 & 1.999 & 1.998 & 2.042 & 1.998 & -46.3 & -0.8 & -46.3 & - & - \\
\hline$C_{2}-l e l_{2} \mathrm{ob}$ & 2.119 & 1.992 & 2.070 & 2.296 & 1.992 & 2.296 & 2.070 & -46.6 & 56.8 & 56.8 & 2.03 & 9.54 \\
\hline TS3 & 2.146 & 2.004 & 2.079 & 2.346 & 1.994 & 2.352 & 2.101 & 3.6 & 57.7 & 57.9 & - & - \\
\hline $\mathrm{lel}_{3}$ & 2.115 & 2.285 & 2.017 & 2.050 & 2.049 & 2.021 & 2.265 & 56.8 & 52.6 & 56.4 & 1.53 & 9.93 \\
\hline \multicolumn{13}{|c|}{$\left[\mathrm{Cu}\left\{\left(\mathrm{NH}_{3}\right)_{2} \mathrm{sar}\right\}\right]^{4+}$} \\
\hline$o b_{3}$ & 2.169 & 2.334 & 2.071 & 2.102 & 2.101 & 2.071 & 2.335 & -43.2 & -42.2 & -43.4 & 0.64 & 13.43 \\
\hline TS1 & 2.174 & 2.078 & 2.121 & 2.316 & 2.070 & 2.361 & 2.096 & -43.1 & -44.7 & -5.6 & - & - \\
\hline $\mathrm{ob}_{2} \mathrm{lel}$ & 2.189 & 2.064 & 2.132 & 2.399 & 2.075 & 2.358 & 2.107 & -43.2 & -45.7 & 60.3 & 1.60 & 11.06 \\
\hline TS2 & 2.195 & 2.063 & 2.175 & 2.386 & 2.101 & 2.332 & 2.113 & -44.8 & -3.8 & 59.8 & - & - \\
\hline $\mathrm{C}_{2}-\mathrm{lel}_{2} \mathrm{ob}$ & 2.208 & 2.077 & 2.158 & 2.389 & 2.077 & 2.389 & 2.158 & -45.7 & 60.0 & 60.0 & 2.56 & 8.27 \\
\hline TS3 & 2.225 & 2.126 & 2.090 & 2.463 & 2.042 & 2.287 & 2.341 & -4.2 & 57.9 & 60.0 & - & - \\
\hline $\mathrm{lel}_{3}$ & 2.239 & 2.079 & 2.465 & 2.193 & 2.233 & 2.398 & 2.068 & 57.0 & 60.4 & 56.8 & 5.70 & 4.21 \\
\hline \multicolumn{13}{|c|}{$\left[\mathrm{Cu}\left\{\left(\mathrm{NMe}_{3}\right)_{2} \operatorname{sar}\right\}\right]^{4+}$} \\
\hline$o b_{3}$ & 2.154 & 2.314 & 2.065 & 2.087 & 2.089 & 2.06 & 2.311 & -43.1 & -42.6 & -43.3 & 0.62 & 13.28 \\
\hline TS1 & 2.16 & 2.065 & 2.113 & 2.294 & 2.061 & 2.34 & 2.087 & -43 & -44.9 & -4.5 & - & - \\
\hline $\mathrm{Ob}_{2} \mathrm{lel}$ & 2.176 & 2.058 & 2.121 & 2.385 & 2.063 & 2.327 & 2.102 & -43.3 & -45.8 & 60.2 & 1.69 & 10.69 \\
\hline TS2 & 2.183 & 2.037 & 2.255 & 2.297 & 2.134 & 2.296 & 2.081 & -45.1 & -2.3 & 58.5 & - & - \\
\hline $\mathrm{C}_{2}-\mathrm{lel}_{2} \mathrm{ob}$ & 2.193 & 2.067 & 2.163 & 2.349 & 2.067 & 2.349 & 2.163 & -45.1 & 59.3 & 59.3 & 2.94 & 7.55 \\
\hline TS3 & 2.212 & 2.155 & 2.069 & 2.36 & 2.043 & 2.188 & 2.456 & -5.3 & 56.5 & 60.1 & - & - \\
\hline $\mathrm{lel}_{3}$ & 2.192 & 2.246 & 2.177 & 2.069 & 2.391 & 2.06 & 2.206 & 60.3 & 56.4 & 56.8 & 6.49 & 3.69 \\
\hline
\end{tabular}

[a] TS1 refers to the transition state for the interconversion between $o b_{3}$ and $o b_{2} l e l$ conformers; TS2 refers to the transition state for the interconversion between $\mathrm{ob}_{2} l e l$ and $l e l_{2} \mathrm{ob}$ conformers; TS3 refers to the transition state for the interconversion between $l e l_{2} \mathrm{Ob}$ and $l e l_{3}$ conformers.

lent $\mathrm{M}-\mathrm{L}$ distances and dihedral angles. Conversely, the structures of the $\mathrm{C}_{2}-\mathrm{Ob}_{2} l e l$ and $\mathrm{C}_{2}-\mathrm{lel}_{2} \mathrm{Ob}$ conformers show non-equivalent $\mathrm{M}-\mathrm{L}$ bond lengths due to the geometrical constraints associated with the macrobicycles, and this displaces their position in the symmetry map towards the $\Delta=$
0.2 curve (note that this is not due to Jahn-Teller effects). In general, the different isomers of $\left[\mathrm{Co}\left\{\left(\mathrm{NH}_{3}\right)_{2} \mathrm{sar}\right\}\right]^{5+}$ and $\left[\mathrm{Co}\left\{\left(\mathrm{NMe}_{3}\right)_{2} \mathrm{sar}\right\}\right]^{5+}$ can be considered very close to the ideal octahedron, with only one structure showing a $\mathrm{S}\left(O_{h}\right)$ value larger than unity. Despite the small differences, a ten- 

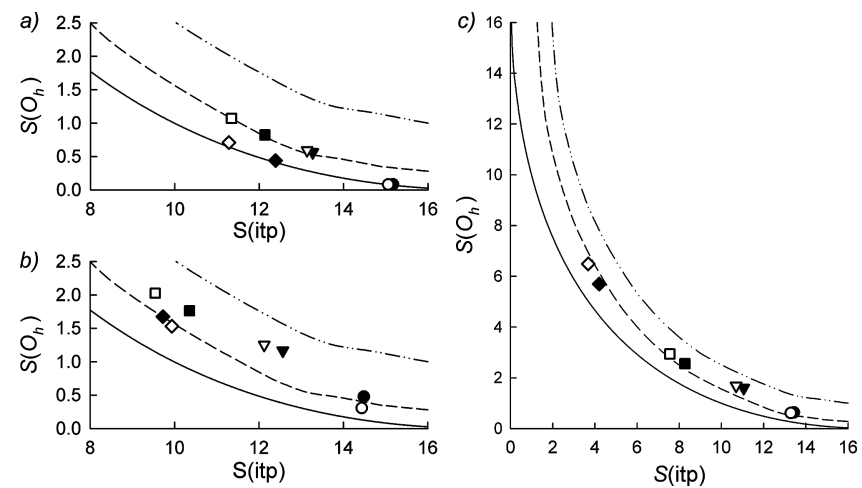

Figure 2. Scatterplots of the octahedron $S\left(O_{h}\right)$ and trigonal prism $S$ (itp) symmetry measures, included in Table 1, for the computed diastereoisomers $\left(o b_{3}=\right.$ circles; $o_{2} l e l=$ triangles; $l e l_{2} o b=$ squares; $\mathrm{lel}_{3}=$ diamonds $)$ of (a) $\left[\mathrm{Co}\left\{\left(\mathrm{NH}_{3}\right)_{2} \mathrm{sar}\right\}\right]^{5+}$ and $\left[\mathrm{Co}\left\{\left(\mathrm{NMe}_{3}\right)_{2} \mathrm{sar}\right\}\right]^{5+}$ (filled and empty symbols, respectively); (b) $\left[\mathrm{Co}\left\{\left(\mathrm{NH}_{3}\right)_{2} \mathrm{sar}\right\}\right]^{4+}$ and $\left[\mathrm{Co}\left\{\left(\mathrm{NMe}_{3}\right)_{2} \mathrm{sar}\right\}\right]^{4+}$ (filled and empty symbols, respectively); (c) $\left[\mathrm{Cu}\left\{\left(\mathrm{NH}_{3}\right)_{2} \mathrm{sar}\right\}\right]^{4+}$ and $\left[\mathrm{Cu}\left\{\left(\mathrm{NMe}_{3}\right)_{2} \mathrm{sar}\right\}\right]^{4+}$ (filled and empty symbols, respectively). The solid line represents the Bailar twist route between the perfect octahedron $\left(O_{h}\right)$ and trigonal prism $\left(D_{3 h}\right)$, considering all metal-ligand bond lengths equal $(\Delta=0.0)$, whereas the dashed and dotted-dashed lines correspond to $\Delta$ values of 0.2 and 0.4 respectively. Note that different scales have been used.

dency towards trigonal-prism geometry can be identified in the graph when going from the $D_{3}-o b_{3}$ conformer to the mixed ob/lel structures $\mathrm{C}_{2}-\mathrm{ob}_{2} l e l$ and $\mathrm{C}_{2}-\mathrm{lel}_{2} \mathrm{Ob}$ intermediates, whereas the formation of the $\mathrm{C}_{3}$-lel $l_{3}$ isomer from $C_{2}$ $\mathrm{lel}_{2} \mathrm{Ob}$ only has the effect of removing the distortion associated with the different $\mathrm{M}-\mathrm{L}$ bond lengths, therefore leading to relatively similar $S$ (itp) values. Reduction of these species into their Jahn-Teller-active $\mathrm{Co}^{\mathrm{II}}$ analogues $\left[\mathrm{Co}\left\{\left(\mathrm{NH}_{3}\right)_{2}\right.\right.$ sar $\}]^{4+}$ and $\left[\mathrm{Co}\left\{\left(\mathrm{NMe}_{3}\right)_{2} \mathrm{sar}\right\}\right]^{4+}$ generates structures with two trans $\mathrm{Co}-\mathrm{N}$ distances longer than the rest by approximately $0.2 \AA$, whereas the average $\mathrm{Co}-\mathrm{N}$ distance increases by approximately $0.1 \AA$ (Table 1 ). Such differences have clear effects on their symmetry maps (see Figure 2, b); the Jahn-Teller distortion shifts the position of the different isomers of $\left[\mathrm{Co}\left\{\left(\mathrm{NH}_{3}\right)_{2} \mathrm{sar}\right\}\right]^{4+}$ and $\left[\mathrm{Co}\left\{\left(\mathrm{NMe}_{3}\right)_{2} \mathrm{sar}\right\}\right]^{4+}$ up to the Bailar twist line with $\Delta=0.2$, whereas their longer $\mathrm{Co}-\mathrm{N}$ distances increase the degree of deviation from the ideal octahedral geometry, especially as the number of straps in the lel conformation increases. Nonetheless, note that all of these structures are still much closer to the octahedron than the trigonal prism. Finally, similar effects are observed on the symmetry map of the isomers of $\left[\mathrm{Cu}\left\{\left(\mathrm{NH}_{3}\right)_{2} \mathrm{sar}\right\}\right]^{4+}$ and $\left[\mathrm{Cu}\left\{\left(\mathrm{NMe}_{3}\right)_{2} \mathrm{sar}\right\}\right]^{4+}$ (Figure 2, c) in the sense that, again, the Jahn-Teller-active nature of these species lead to geometries along the Bailar twist line with $\Delta=0.2$. More importantly, the larger atomic radius of $\mathrm{Cu}^{\mathrm{II}}$ promotes deviations on the $S\left(O_{h}\right)$ and $S$ (itp) values much more significantly than on the previous cobalt complexes. In fact, whereas $o b_{3}-\left[\mathrm{Cu}\left\{\left(\mathrm{NH}_{3}\right)_{2} \mathrm{Sar}\right\}\right]^{4+}$ and $o b_{3}-[\mathrm{Cu}-$ $\left.\left\{\left(\mathrm{NMe}_{3}\right)_{2} \mathrm{Sar}\right\}\right]^{4+}$ show $S\left(O_{h}\right)$ and $S($ itp $)$ values quite close to the ideal octahedron $\left[S\left(O_{h}\right)<1\right]$, the geometries of their $\mathrm{lel}_{3}$ analogues can be considered as distorted trigonal prisms. Such change in the coordination environment around the metal centre, associated with its larger radius, will indeed have an impact on the relative stability of the diastereoisomers (see below).

\section{Energetic and Distortion/Interaction Analysis}

Figure 3 includes plots of the relative free energies in solution $\left(\Delta G_{\mathrm{sol}}\right)$ for all the studied metal-ligand combinations, using their $o b_{3}$ conformations as relative zero. In all cases the activation barriers associated with the interconversion between diastereoisomers lie in the range of 5 to $10 \mathrm{kcal} \mathrm{mol}^{-1}$, which indicate that formation of the thermodynamically more stable isomers should be relatively fast at room temperature. Specifically, the plots for $\left[\mathrm{Co}\left\{\left(\mathrm{NH}_{3}\right)_{2}\right.\right.$ sar $\}]^{5+}$ and $\left[\mathrm{Co}\left\{\left(\mathrm{NMe}_{3}\right)_{2} \mathrm{sar}\right\}\right]^{5+}$ show computed free-energy differences between their $o b_{3}$ and $l e l_{3}$ conformations smaller than $3 \mathrm{kcal} \mathrm{mol}^{-1}$, with intermediate energies for $\mathrm{ob}_{2} l e l$ and $\mathrm{C}_{2}-\mathrm{lel}_{2} \mathrm{ob}$. Their relatively similar thermodynamic stability indicates that mixtures of different conformers are likely to exist in solution, although it is worth noting that despite the errors associated with DFT calculations at this level of theory, the data agrees with the experimental observation of $\operatorname{lel}_{3}-\left[\mathrm{Co}\left\{\left(\mathrm{NH}_{3}\right)_{2} \mathrm{sar}\right\}\right]^{5+}$ and $\mathrm{ob}_{3}-\left[\mathrm{Co}\left\{\left(\mathrm{NMe}_{3}\right)_{2}-\right.\right.$ sar $\}]^{5+}$ in solution. Reduction of these complexes into their $\mathrm{Co}^{\mathrm{II}}$ analogues (see Figure 3, b) has, roughly, the effect of decreasing the free-energy difference between the $\operatorname{lel}_{3}$ - and $o b$-containing conformers by approximately $2-3 \mathrm{kcal} \mathrm{mol}^{-1}$. In agreement with the experiments, such a subtle energy
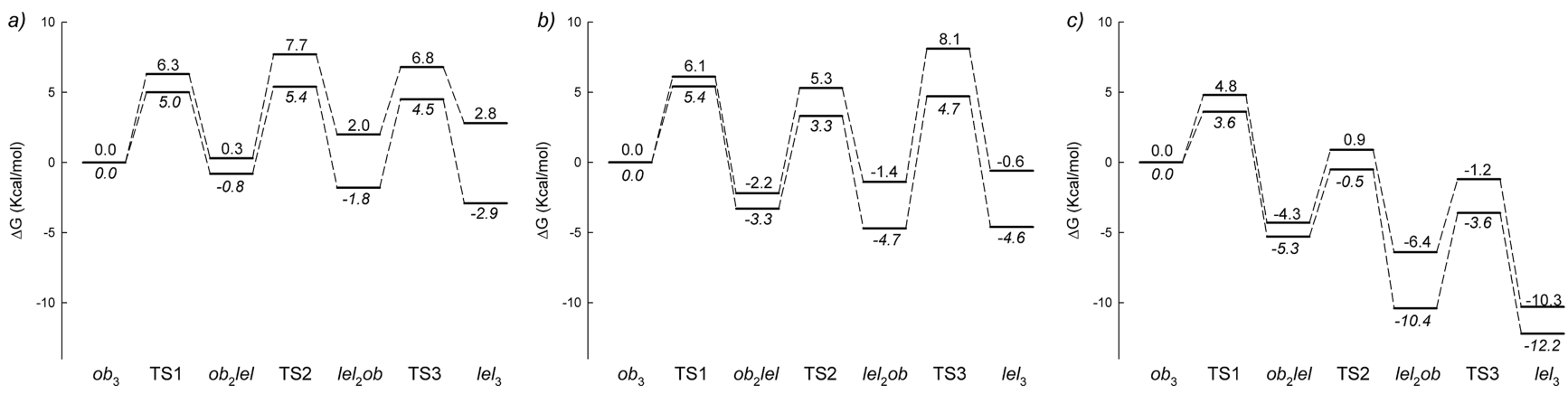

Figure 3. Solution-free energy profiles (in $\mathrm{kcal} \mathrm{mol}^{-1}$ ) for the interconversion between the computed diastereoisomers of $(\mathrm{a})\left[\mathrm{Co}_{\{}\left(\mathrm{NH}_{3}\right)_{2}{ }^{-}\right.$ sar $\}]^{5+}$ (italics) and $\left[\mathrm{Co}\left\{\left(\mathrm{NMe}_{3}\right)_{2} \mathrm{sar}\right\}\right]^{5+}$ (non-italic); (b) $\left[\mathrm{Co}\left\{\left(\mathrm{NH}_{3}\right)_{2} \mathrm{sar}\right\}\right]^{4+}$ (italics) and $\left[\mathrm{Co}\left\{\left(\mathrm{NMe}_{3}\right)_{2} \mathrm{sar}\right\}\right]^{4+}(\mathrm{non}-\mathrm{italic}) ;(\mathrm{c})\left[\mathrm{Cu}\left\{(\mathrm{NH})_{2}\right)_{2}\right.$ sar $\}]^{4+}$ (italics) and $\left[\mathrm{Cu}\left\{\left(\mathrm{NMe}_{3}\right)_{2} \mathrm{sar}\right\}\right]^{4+}$ (non-italic). In all cases, the corresponding $o b_{3}$ conformation was used as relative zero. 
change would make the $\mathrm{lel}_{3}$ conformers of $\left[\mathrm{Co}\left\{\left(\mathrm{NH}_{3}\right)_{2}\right.\right.$ $\operatorname{sar}\}]^{4+}$ and $\left[\mathrm{Co}\left\{\left(\mathrm{NMe}_{3}\right)_{2} \mathrm{Sar}\right\}\right]^{4+}$ more stable than the others, however, the plots also indicate that these are not the computed most stable minima but the ob $b_{2} l e l-[\mathrm{Co}-$ $\left.\left\{\left(\mathrm{NH}_{3}\right)_{2} \mathrm{sar}\right\}\right]^{4+}$ and $l e l_{2} \mathrm{ob}-\left[\mathrm{Co}\left\{\left(\mathrm{NMe}_{3}\right)_{2} \mathrm{sar}\right\}\right]^{4+}$, a discrepancy below the level of accuracy that can be obtained with the employed methodology. The diastereoisomers of $\left[\mathrm{Cu}\left\{\left(\mathrm{NH}_{3}\right)_{2} \mathrm{sar}\right\}\right]^{4+}$ and $\left[\mathrm{Cu}\left\{\left(\mathrm{NMe}_{3}\right)_{2} \mathrm{sar}\right\}\right]^{4+}$ show, conversely, a different behaviour (see Figure 3, c). Here the plots indicate that the series of isomerisations from the $o b_{3}$ to $\mathrm{lel}_{3}$ conformers are clearly exergonic, with little difference regardless of the sarcophagine ligand. Moreover, comparison of the activation barriers for these isomerisations and those for the reverse reactions (i.e., $l e l \rightarrow o b$ isomerisations) shows that the latter are approximately twice those of the former, thus pointing towards a higher inertness of $\mathrm{lel}_{3}$ versus $o b_{3}$ conformers of these $\mathrm{Cu}^{\mathrm{II}}$ complexes. Overall, the
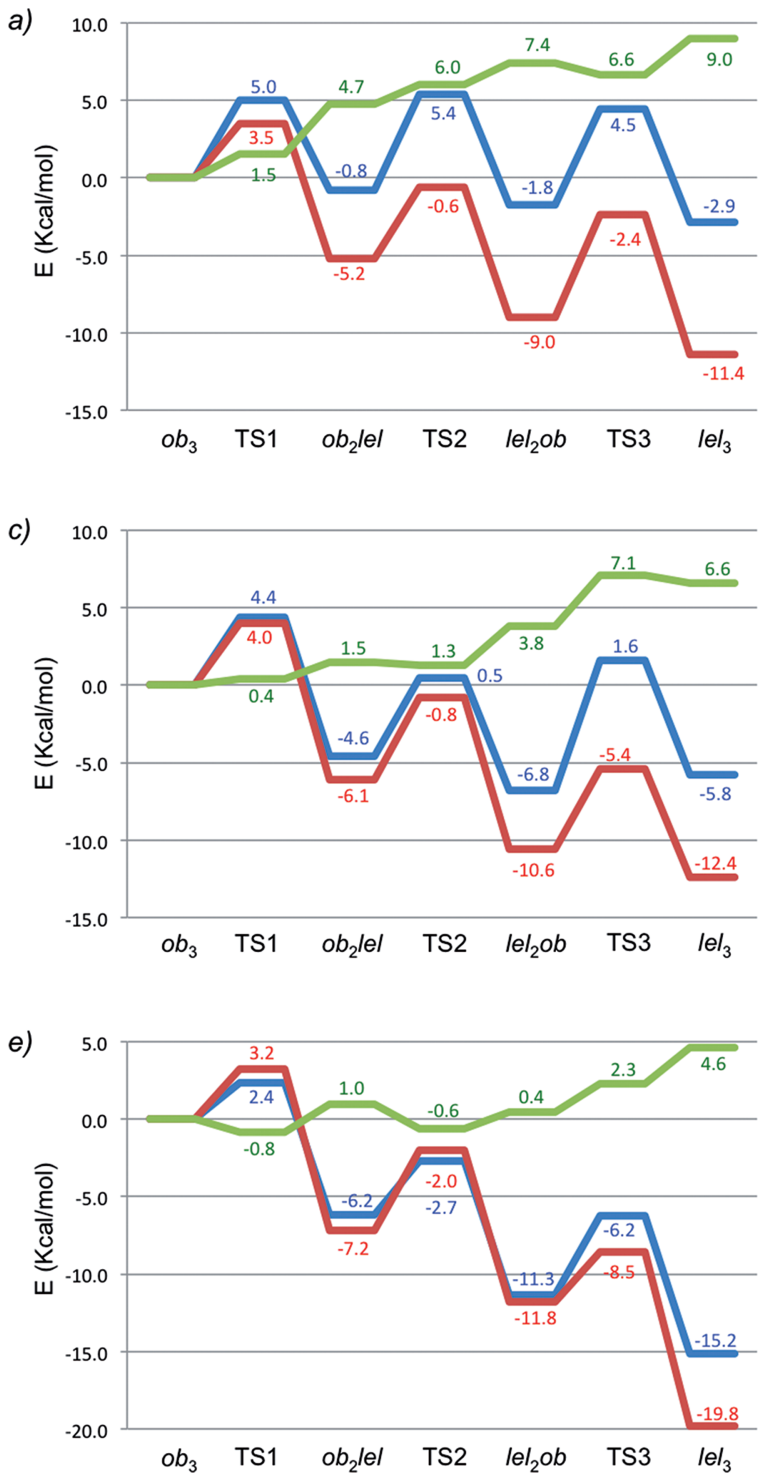

computations agree with the experimental observation of the $\mathrm{lel}_{3}$ form for all the existing $\mathrm{Cu}^{\mathrm{II}}$-sarcophagine complexes, and this seems to be associated with the distortions from the octahedral geometry that these species present, as revealed by their symmetry maps in Figure 2 (c).

Despite the agreement between computational and experimental data, the relationship between factors such as the atomic radius of the metal centre, its coordination environment and the relative stability of the different isomers was not completely clear at this point, so a further distortion/interaction analysis was carried out. This analysis, made on the basis of electronic energies in solution $\left(\Delta E_{\mathrm{sol}}\right)$, has been performed in a relative manner and the changes in the stability of both ground- and transition-state structures for each metal-ligand system were compared with their $o b_{3}$ conformations (see the Computational Details). Thus, the changes in $\Delta E_{\text {sol }}$ have been dissected into two
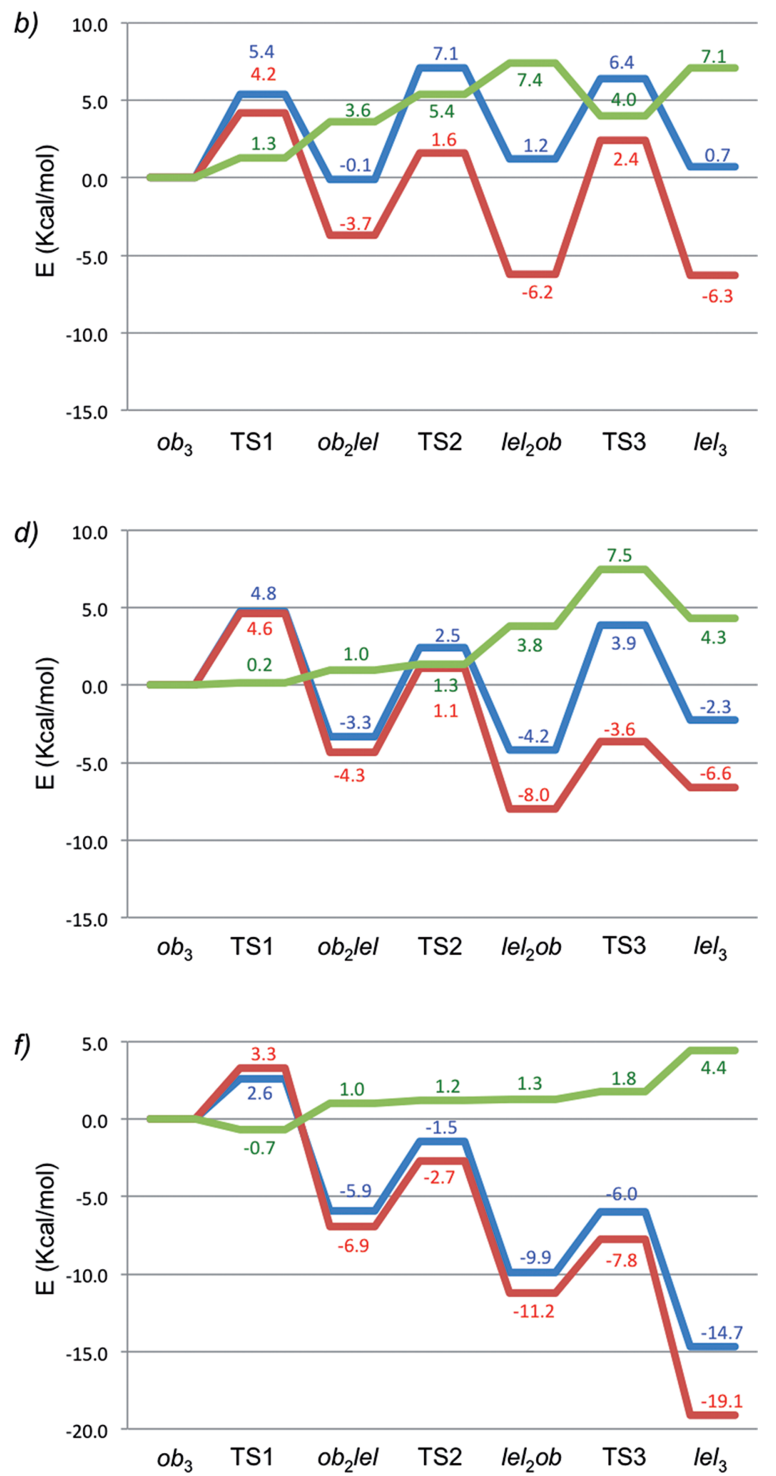

Figure 4. Distortion-interaction energy analysis (in $\left.\mathrm{kcalmol}^{-1}\right)$ for the different diastereoisomers of (a) $\left[\mathrm{Co}\left\{\left(\mathrm{NH}_{3}\right)_{2} \mathrm{sar}\right]^{5+}\right.$; (b) $\left[\mathrm{Co}\left\{\left(\mathrm{NMe}_{3}\right)_{2} \mathrm{Sar}\right\}\right]^{5+}$; (c) $\left[\mathrm{Co}\left\{\left(\mathrm{NH}_{3}\right)_{2} \mathrm{sar}\right\}\right]^{4+}$; (d) $\left[\mathrm{Co}\left\{\left(\mathrm{NMe}_{3}\right)_{2} \mathrm{sar}\right\}\right]^{4+}$; (e) $\left[\mathrm{Cu}\left\{\left(\mathrm{NH}_{3}\right)_{2} \mathrm{sar}\right\}\right]^{4+}$; (f) $\left[\mathrm{Cu}\left\{\left(\mathrm{NMe}_{3}\right)_{2} \mathrm{Sar}\right\}\right]^{4+}$. Blue $=\Delta E_{\mathrm{sol}}$; red $=$ $\Delta E_{\text {dist }}$, green $=\Delta E_{\text {int }}$. Note that different scales have been used. 
terms [see Equation (2) in the Computational Details]: $\Delta E_{\text {dist }}$, the change in the relative energy of the sarcophagine ligand from its geometry on the $o b_{3}$ conformer to the specific analysed structure; and $\Delta E_{\text {int }}$, the change in the metalligand interaction energy. The results of such analysis are given in Figure 4. Importantly, despite not including entropic, enthalpic, and dispersion corrections, it is worth noting that $\Delta E_{\text {sol }}$ values follow the same trends as the previously shown free energy values, leading to similar stabilities for the four conformers of each $\mathrm{Co}^{\mathrm{III}}$ complex, a slight stabilisation of the lel-containing conformers of the complexes with $\mathrm{Co}^{\mathrm{II}}$ and a noticeable stabilisation of the $\mathrm{lel}_{3}$ conformers of the $\mathrm{Cu}^{\mathrm{II}}$ complexes. In all cases, decomposition of the $\Delta E_{\text {sol }}$ values into $\Delta E_{\text {int }}$ and $\Delta E_{\text {dist }}$ indicates that the $o b_{3} \rightarrow l e l_{3}$ series of isomerisations generate structures in which the sarcophagine ligand adopts more stable conformations (negative $\Delta E_{\text {dist }}$ values), therefore contributing to the stabilisation of the $\mathrm{lel}_{3}$ isomers. Note that such conclusion has already been drawn on the basis of molecular mechanics calculations. ${ }^{[14]}$ Conversely, these isomerisations also imply a gradual decrease in the $\mathrm{M}-\mathrm{L}$ bonding interaction (positive $\Delta E_{\text {int }}$ values), and this favours the formation of $o b_{3}$ isomers. Evidently, the final outcome depends on the relative magnitude of the two terms. In this sense, it worth noting that there is a certain degree of parallelism between the $\Delta E_{\text {dist }}$ and $\Delta E_{\text {sol }}$ curves, which indicates that the activation barriers for these interconversions are mainly associated with the energy required for the sarcophagine ligand to rearrange into the transition-state geometry. As commented upon previously, these feature $\mathrm{N}-\mathrm{C}-\mathrm{C}-\mathrm{N}$ dihedral angles of the central en chelate ring typically close to zero.

In greater detail, comparison of the plots for the groundstate structures of $\left[\mathrm{Co}\left\{\left(\mathrm{NH}_{3}\right)_{2} \mathrm{Sar}\right\}\right]^{5+}$ and $\left[\mathrm{Co}\left\{\left(\mathrm{NMe}_{3}\right)_{2^{-}}\right.\right.$ sar $\}]^{5+}$ shows differences of approximately $2 \mathrm{kcal} \mathrm{mol}^{-1}$ on the $\Delta E_{\text {int }}$ values for their lel $_{3}$ conformers $(9.0$ and $7.1 \mathrm{kcal} \mathrm{mol}^{-1}$, respectively), and $5 \mathrm{kcal} \mathrm{mol}^{-1}$ on $\Delta E_{\text {dist }}(-11.4$ versus $-6.3 \mathrm{kcal} \mathrm{mol}^{-1}$, respectively), therefore implicating the different $\Delta E_{\text {dist }}$ values associated with the nature of the sarcophagine ligand as the key factor behind the observation of $l e l_{3}-\left[\mathrm{Co}\left\{\left(\mathrm{NH}_{3}\right)_{2} \mathrm{sar}\right\}\right]^{5+}$ and $o b_{3}-\left[\mathrm{Co}\left\{\left(\mathrm{NMe}_{3}\right)_{2} \mathrm{sar}\right\}\right]^{5+}$. Interestingly, analysis of the distortion/interaction diagrams for their reduced analogues $\left[\mathrm{Co}\left\{\left(\mathrm{NH}_{3}\right)_{2} \mathrm{Sar}\right\}\right]^{4+}$ and $\left[\mathrm{Co}\left\{\left(\mathrm{NMe}_{3}\right)_{2} \mathrm{sar}\right\}\right]^{4+}$ show almost identical values for the $\Delta E_{\mathrm{dist}}$ term along the $\mathrm{ob}_{3} \rightarrow l e l_{3}$ series of isomerisations, which indicate that the effect of the macrobicycle remains constant. On the contrary, a decrease of approximately $3 \mathrm{kcalmol}^{-1}$ is computed for the $\Delta E_{\text {int }}$ values, a change attributable to the different oxidation state (and radius) of the metal centre. As a result, the $\mathrm{lel}_{3}$ conformers of these $\mathrm{Co}^{\mathrm{II}}$ complexes are stabilised. Finally, the data for $\left[\mathrm{Cu}\left\{\left(\mathrm{NH}_{3}\right)_{2}-\right.\right.$ sar $\}]^{4+}$ and $\left[\mathrm{Cu}\left\{\left(\mathrm{NMe}_{3}\right)_{2} \operatorname{sar}\right\}\right]^{4+}$ again show significant differences with respect to the previous cobalt complexes. Here the formation of the $\mathrm{lel}_{3}$ conformers leads to ligand stabilisations of approximately $20 \mathrm{kcal} \mathrm{mol}^{-1}$, whereas the overall change in metal-ligand interaction energy is always smaller than $5 \mathrm{kcalmol}^{-1}$. As a result, the distortion/interaction analysis on these $\mathrm{Cu}^{\mathrm{II}}$ species indicates that the origin of the large stabilisation of the $\mathrm{lel}_{3}$ conformers is due to the geometry that the sarcophagine ligand itself is able to adopt when bound to $\mathrm{Cu}^{\mathrm{II}}$. Combined with the symmetry maps in Figure 3, the results point towards the distortion that these structures present with respect to the ideal octahedron as the origin of such stabilisation.

\section{Conclusion}

DFT methods have been used to compute the free-energy profile associated with the interconversion between the different isomers of the complexes that $\mathrm{Co}^{\mathrm{III}}, \mathrm{Co}^{\mathrm{II}}$ and $\mathrm{Cu}^{\mathrm{II}}$ form with the sarcophagine ligands $\left\{\left(\mathrm{NH}_{3}\right)_{2}-\right.$ sar $\}^{2+}$ and $\left\{\left(\mathrm{NMe}_{3}\right)_{2} \mathrm{sar}\right\}^{2+}$. In all cases, the activation barriers were found to be lower than $10 \mathrm{kcal} \mathrm{mol}^{-1}$, therefore ensuring that the observed conformers in solution at room temperature correspond to the global minima (i.e., those with the lowest relative free energy). For the studied $\mathrm{Co}^{\mathrm{III}}$ and $\mathrm{Co}^{\mathrm{II}}$ complexes the computations show that in general all isomers present similar free energies, and this explains why the mere change of the groups bound to the apical nitrogen atoms leads, in some cases, to a different behaviour. Despite the limitations of the employed methodology, the results agree with the available experimental information in the sense that, when the relative stability of $l e l_{3}$ and $o b_{3}$ conformers are compared, the $\mathrm{lel}_{3}$ form is favoured for $\left[\mathrm{Co}\left\{\left(\mathrm{NH}_{3}\right)_{2} \mathrm{sar}\right\}\right]^{5+},\left[\mathrm{Co}\left\{\left(\mathrm{NH}_{3}\right)_{2} \mathrm{sar}\right\}\right]^{4+}$ and $\left[\mathrm{Co}\left\{\left(\mathrm{NMe}_{3}\right)_{2}-\right.\right.$ $\operatorname{sar}\}]^{4+}$, whereas $\left[\mathrm{Co}\left\{\left(\mathrm{NMe}_{3}\right)_{2} \mathrm{sar}\right\}\right]^{5+}$ prefers the $o b_{3}$ conformation. Importantly, this adds further support to the hypothesis of a conformational change associated with the slower electron self-exchange process observed for [Co$\left.\left\{\left(\mathrm{NMe}_{3}\right)_{2} \mathrm{Sar}\right\}\right]^{5+/ 4+}$ compared to the $\left[\mathrm{Co}\left\{\left(\mathrm{NH}_{3}\right)_{2} \mathrm{sar}\right\}\right]^{5+/ 4+}$ couple. ${ }^{[2 a]}$ Conversely, the free-energy profile for the interconversion between the different isomers of $\left[\mathrm{Cu}\left\{\left(\mathrm{NH}_{3}\right)_{2}-\right.\right.$ sar $\}]^{4+}$ and $\left[\mathrm{Cu}\left\{\left(\mathrm{NMe}_{3}\right)_{2} \mathrm{sar}\right\}\right]^{4+}$ indicates that these species have a marked tendency to adopt the $\mathrm{lel}_{3}$ form (free energies 10.3 and $12.2 \mathrm{kcal} \mathrm{mol}^{-1}$ lower than the corresponding $o b_{3}$ structures, respectively) regardless of the nature of the substituents at the apical nitrogen atoms, an observation in agreement with the lack of $o b_{3}$ complexes between $\mathrm{Cu}^{\mathrm{II}}$ and sar or sar-derived ligands in solution.

The structure and relative stability of all of these species have been further analysed by combining CSM with a distortion/interaction energy analysis. The latter has been carried out by considering the metal and ligand as two different fragments, thereby allowing us to dissect the relative stability (always using the corresponding $o b_{3}$ conformer as a reference) of each isomer in two contributions, the interaction energy between metal and ligand, and the stability of the ligand itself. The distortion/interaction energy analysis of all the studied complexes shows a similar trend along the $o b_{3} \rightarrow l e l_{3}$ series of isomerisations, with the ligand gradually adopting more stable geometries at the same time as its interaction with the metal weakens. For the $\mathrm{Co}^{\mathrm{II}}$ and $\mathrm{Co}^{\mathrm{III}}$ complexes these two terms remain almost equal in magnitude but have opposite signs, thus leading to similar stabilities for each set of four isomers. Conversely, for the $\mathrm{Cu}^{\mathrm{II}}$ complexes, the increase in ligand stability largely out- 
performs the change in interaction energy, driving the formation of $l e l_{3}-\left[\mathrm{Cu}\left\{\left(\mathrm{NH}_{3}\right)_{2} \mathrm{Sar}\right\}\right]^{4+}$ and lel $_{3}-\left[\mathrm{Cu}\left\{\left(\mathrm{NMe}_{3}\right)_{2}-\right.\right.$ $\operatorname{sar}\}]^{4+}$. The CSM analysis also shows significant geometric differences between the $\mathrm{Co}^{\mathrm{II}}$ and $\mathrm{Co}^{\mathrm{III}}$ complexes, which can all be considered as distorted octahedra, and the $\mathrm{Cu}^{\mathrm{II}}$ complexes, which tend to generate geometries closer to the trigonal prism as the number of straps in the lel orientation increases. All in all, the results confirm the existence of a clear relationship between the stability of a given structure and its degree of distortion with respect to the ideal octahedron (or trigonal prism), ${ }^{[2 c]}$ the latter being ultimately dependent on the transition metal and its radius.

\section{Computational Details}

The DFT calculations reported in this work have been carried out using the Gaussian 09 (Revision A.02) package ${ }^{[18]}$ and the BP86 functional. ${ }^{[19]}$ Spin-unrestricted calculations were performed for the paramagnetic species. Geometries were optimised using the 6$31 \mathrm{G}(\mathrm{d}, \mathrm{p})$ basis set ${ }^{[20]}$ for $\mathrm{C}, \mathrm{N}$ and $\mathrm{H}$, whereas the Stuttgart relativistic effective-core potentials (RECPs) and associated basis sets ${ }^{[21]}$ were used for $\mathrm{Co}$ and $\mathrm{Cu}$ (BS1). All stationary points were fully characterised by means of analytical frequency calculations as either minima (all positive eigenvalues) or transition states (one negative eigenvalue), and IRC calculations and subsequent geometry optimisations were used to confirm the minima linked by each transition state. The reported Gibbs free energies in solution $\left(G_{\mathrm{sol}}\right)$ were obtained by adding zero-point and thermal effects at $298.15 \mathrm{~K}$, as well as D3(BJ) dispersion effects, ${ }^{[22]}$ to the electronic energies in solution $\left(E_{\mathrm{sol}}\right)$, computed by single-point calculations on the previously optimised structures using a larger basis-set system (BS2), and also including solvent effects by using the polarizable continuum model (PCM) method (standard options, water as solvent). ${ }^{[23]} \mathrm{BS} 2$ only differs from BS1 in the employment of the cc-pVTZ basis set ${ }^{[24]}$ for all the non-metal atoms.

Additional single-point calculations, at the BP86/cc-pVTZ level and with solvent effects included by using the PCM method, were performed on the previously optimised metal-ligand complexes after removing the transition-metal atom. These were used for the distortion/interaction analysis of the different stationary points (both minima and transition states) associated with each studied transition-metal complex. Distortion/interaction analysis is a fragment approach, initially employed to study bimolecular reactions, and in which the PES constructed from a series of stationary points (non-stationary points can also be used) is decomposed in two terms [Equation (1)]: $\Delta E_{\text {dist }}$, the energy associated with distorting the reactants (i.e., fragments) from their reference state into their specific conformation on the PES, and $\Delta E_{\text {int }}$, the interaction energy between those fragments. ${ }^{[25]}$ In the present case, such an approach has been employed to gain more insight into the relative stability of the diastereoisomeric structures of a series of metal-sarcophagine complexes and the transition states for their interconversion, and this required some modifications. First, the analyses were carried out in a relative manner, that is, using the solution electronic energy of the $o b_{3}$ conformation of each studied transition-metal complex as relative zero. Second, the fragments were selected as metal (fragment 1) and sarcophagine ligand (fragment 2). Thus, due to the monoatomic nature of fragment 1, the $\Delta E_{\text {dist }}$ term in Equation (1) (which encompasses the distortion energy associated with the two fragments) simplifies to that of only the sarcophagine ligand, see Equation (2).
$\Delta E_{\mathrm{sol}}=\Delta E_{\mathrm{dist}}+\Delta E_{\mathrm{int}}$

$\Delta E_{\mathrm{sol}}=\Delta E_{\mathrm{dist}}($ ligand $)+\Delta E_{\mathrm{int}}($ metal-ligand $)$

The CSM approach ${ }^{[17 a]}$ has been used to quantitatively assess the degree of symmetry of the optimised transition-metal complexes. $S\left(O_{h}\right)$ and $S$ (itp) indexes of each isomer were obtained after introducing the Cartesian coordinates of the transition metal and its six bound nitrogen atoms into the online application available at http:// www.csm.huji.ac.il/.

\section{Acknowledgments}

Prof. M. G. Basallote (University of Cádiz, Spain) is acknowledged for careful reading of the manuscript and for useful comments.

[1] a) L. F. Lindoy, K.-M. Park, S. S. Lee, Chem. Soc. Rev. 2013, 42, 1713-1727; b) L. F. Lindoy, B. Dietrich, P. Viout, J.-M. Lehn, The Chemistry of Macrocyclic Ligand Complexes, Cambridge University Press, Cambridge, UK, 1989; c) J.-M. Lehn, Supramolecular Chemistry, Wiley-VCH, Weinheim, Germany, 1995.

[2] a) P. V. Bernhardt, A. M. T. Bygott, R. J. Geue, A. J. Hendry, B. R. Korybut-Daszkiewicz, P. A. Lay, J. R. Pladziewicz, A. M. Sargeson, A. C. Willis, Inorg. Chem. 1994, 33, 4553-4561; b) P. V. Bernhardt, R. Bramley, L. M. Engelhardt, J. M. Harrowfield, D. C. R. Hockless, B. R. Korybut-Daszkiewicz, E. R. Krausz, T. Morgan, A. M. Sargeson, Inorg. Chem. 1995, 34, 3589-3599; c) P. Comba, A. M. Sargeson, L. M. Engelhardt, J. M. Harrowfield, A. H. White, E. Horn, M. R. Snow, Inorg. Chem. 1985, 24, 2325-2327; d) A. M. Sargeson, Coord. Chem. Rev. 1996, 151, 89-114; e) G. A. Bottomley, I. J. Clark, I. I. Creaser, L. M. Engelhardt, R. J. Geue, K. S. Hagen, J. M. Harrowfield, G. A. Lawrance, P. A. Lay, A. M. Sargeson, A. J. See, B. W. Skelton, A. H. White, F. R. Wilner, Aust. J. Chem. 1994, 47, 143-179; f) P. Anderson, I. Creaser, C. Dean, J. Harrowfield, E. Horn, L. Martin, A. Sargeson, M. Snow, E. Tiekink, Aust. J. Chem. 1993, 46, 449-463.

[3] a) B. M. Paterson, P. Roselt, D. Denoyer, C. Cullinane, D. Binns, W. Noonan, C. M. Jeffery, R. I. Price, J. M. White, R. J. Hicks, P. S. Donnelly, Dalton Trans. 2014, 43, 1386-1396; b) S. L. Liu, Z. Li, P. S. Conti, Molecules 2014, 19, 4246-4255; c) K. V. Tan, P. A. Pellegrini, B. W. Skelton, C. F. Hogan, I. Greguric, P. J. Barnard, Inorg. Chem. 2013, 52, 468-477; d) T. J. Wadas, E. H. Wong, G. R. Weisman, C. J. Anderson, Chem. Rev. 2010, 110, 2858-2902; e) M. T. Ma, M. S. Cooper, R. L. Paul, K. P. Shaw, J. A. Karas, D. Scanlon, J. M. White, P. J. Blower, P. S. Donnelly, Inorg. Chem. 2011, 50, 6701-6710.

[4] K. A. Jensen, Inorg. Chem. 1970, 9, 1-5.

[5] Note that the IUPAC nomenclature for the $o b$ and lel isomers is $\delta$ and $\lambda$, respectively. Thus, for instance $\Delta-o b_{2} l e l=\Delta(\delta \delta \lambda)$.

[6] A. M. Sargeson, Pure Appl. Chem. 1986, 58, 1511-1522.

[7] I. B. Bersuker, The Jahn-Teller Effect, Cambridge University Press, 2006.

[8] a) B. Murphy, B. Hathaway, Coord. Chem. Rev. 2003, 243, 237262; b) I. B. Bersuker, Chem. Rev. 2001, 101, 1067-1114.

[9] For a study in which Jahn-Teller isomers of hexacoordinate copper(II) complexes have been trapped and characterised, see: P. Comba, A. Hauser, M. Kerscher, H. Pritzkow, Angew. Chem. Int. Ed. 2003, 42, 4536-4540; Angew. Chem. 2003, 115, 4675.

[10] M. A. Halcrow, Chem. Soc. Rev. 2013, 42, 1784-1795.

[11] a) S. G. Taylor, M. R. Snow, T. W. Hambley, Aust. J. Chem. 1983, 36, 2359-2368; b) P. Comba, A. Fath, A. Kuhner, B. Nuber, J. Chem. Soc., Dalton Trans. 1997, 1889-1898; c) A. M. T. Bygott, A. M. Sargeson, Inorg. Chem. 1998, 37, 4795-4806; d) T. W. Hambley, J. Comput. Chem. 1987, 8, 651-657.

[12] P. Comba, Coord. Chem. Rev. 1999, 182, 343-371.

[13] P. Comba, A. F. Sickmüller, Inorg. Chem. 1997, 36, 4500-4507. 
[14] P. Comba, Inorg. Chem. 1989, 28, 426-431.

[15] a) M. Atanasov, C. Daul, P. L. W. Tregenna-Piggott, Vibronic Interactions and the Jahn-Teller Effect: Theory and Applications, Springer, 2011; b) R. G. McKinlay, J. M. Zurek, M. J. Paterson, in: Advances in Inorganic Chemistry, vol. 62 (Eds.: R. V. Eldik, J. Harvey), Academic Press, 2010, p. 351-390.

[16] Cartesian coordinates and energetic data for all the optimised species are included in the Supporting Information.

[17] a) S. Alvarez, P. Alemany, D. Casanova, J. Cirera, M. Llunell, D. Avnir, Coord. Chem. Rev. 2005, 249, 1693-1708; b) S. Alvarez, D. Avnir, M. Llunell, M. Pinsky, New J. Chem. 2002, 26, 996-1009.

[18] M. J. Frisch, G. W. Trucks, H. B. Schlegel, G. E. Scuseria, M. A. Robb, J. R. Cheeseman, G. Scalmani, V. Barone, B. Mennucci, G. A. Petersson, H. Nakatsuji, M. Caricato, X. Li, H. P. Hratchian, A. F. Izmaylov, J. Bloino, G. Zheng, J. L. Sonnenberg, M. Hada, M. Ehara, K. Toyota, R. Fukuda, J. Hasegawa, M. Ishida, T. Nakajima, Y. Honda, O. Kitao, H. Nakai, T. Vreven, J. A. Montgomery Jr., J. E. Peralta, F. Ogliaro, M. Bearpark, J. J. Heyd, E. Brothers, K. N. Kudin, V. N. Staroverov, R. Kobayashi, J. Normand, K. Raghavachari, A. Rendell, J. C. Burant, S. S. Iyengar, J. Tomasi, M. Cossi, N. Rega, J. M. Millam, M. Klene, J. E. Knox, J. B. Cross, V. Bakken, C. Adamo, J. Jaramillo, R. Gomperts, R. E. Stratmann, O. Yazyev,
A. J. Austin, R. Cammi, C. Pomelli, J. W. Ochterski, R. L. Martin, K. Morokuma, V. G. Zakrzewski, G. A. Voth, P. Salvador, J. J. Dannenberg, S. Dapprich, A. D. Daniels, O. Farkas, J. B. Foresman, J. V. Ortiz, J. Cioslowski, D. J. Fox, Gaussian 09, revision A.02, Gaussian, Inc., Wallingford, CT, 2009.

[19] a) A. D. Becke, Phys. Rev. A 1988, 38, 3098; b) J. P. Perdew, Phys. Rev. B 1986, 33, 8822.

[20] a) P. C. Harihanan, J. A. Pople, Theor. Chim. Acta 1973, 28, 213-222; b) W. J. Hehre, R. Ditchfield, J. A. Pople, J. Chem. Phys. 1972, 56, 2257-2261.

[21] D. Andrae, U. Haussermann, M. Dolg, H. Stoll, H. Preuss, Theor. Chim. Acta 1990, 77, 123.

[22] S. Grimme, J. Antony, S. Ehrlich, H. Krieg, J. Chem. Phys. 2010, 132, 154104.

[23] a) J. Tomasi, B. Mennucci, R. Cammi, Chem. Rev. 2005, 105, 2999-3093; b) M. Cossi, G. Scalmani, N. Rega, V. Barone, J. Chem. Phys. 2002, 117, 43-54.

[24] T. H. Dunning, J. Chem. Phys. 1989, 90, 1007-1023.

[25] a) W.-J. van Zeist, F. M. Bickelhaupt, Org. Biomol. Chem. 2010, 8, 3118-3127; b) D. H. Ess, K. N. Houk, J. Am. Chem. Soc. 2007, 129, 10646-10647.

Received: October 13, 2014

Published Online: December 22, 2014 